\title{
La semántica de la maternidad. Fecundidad, esterilidad y esclavas en el Antiguo Israel*
}

\author{
Clara Carbonell Ortiz** \\ Universidad Complutense de Madrid \\ ORCID ID: https://orcid.org/0000-0002-9173-846X
}

El presente artículo analiza el discurso sobre la naturaleza procreadora de las mujeres tal y como aparece reflejado en la lengua hebrea bíblica. Haciendo uso de una perspectiva de género y una metodología filológica, se estudian diversas raíces (על על עק"ר, שכ"ל , יל"ד) y una expresión idiomática (יל"ד על ברכ-) que continúan siendo objeto de debate académico hasta la fecha y que aparecen empleadas para describir -y prescribir- el rol reproductivo de la mujer israelita. La nominalización de la maternidad, su ausencia y el recurso a la explotación de esclavas como solución ante la falta de descendencia son los temas que esta investigación pretende abordar. Se dedica especial atención a la semántica del lexema עקרה, discutiendo su traducción convencional de 'estéril' y realizando una propuesta que, si bien no completamente novedosa, nunca ha sido sometida a una argumentación minuiciosa.

Palabras Clave: Filología Hebrea; hermenéutica bíblica feminista; reproducción; sexualidad femenina; semántica; mujeres israelitas.

The Semantics of Motherhood. Fertility, Barrenness and Female Slaves in ANCIENT ISRAEL.- This article analyses the discourse on female procreating nature as reflected in Biblical Hebrew. Adopting a gender perspective and using a philological method, I study an array of roots (יל"יד על ברכ-) , שכ"ל , יל"ד) and one idiomatic expression which are objects of scholarly debate and which were employed to describe -and prescribe- the reproductive role of Israelite women. The naming of motherhood, its absence and the resort to slave exploitation as a way to end childlessness are the topics which this piece of research aims to address. Special attention is drawn to the semantics of the lexeme עקרה, where I discuss its conventional rendering as "barren" and make a proposal which, albeit not completely new, has never been thoroughly justified.

Keywords: Hebrew Philology; Feminist Biblical Hermeneutics; Reproduction; Female sexuality; Semantics; Israelite women.

* El proyecto que ha generado estos resultados ha contado con el apoyo de una beca de la Fundación Bancaria La Caixa (ID 100010434), cuyo código es LCF/BQ/ ES18/11670004.

**clarcarb@ucm.es

Copyright: (C) 2019 CSIC. Este es un artículo de acceso abierto distribuido bajo los términos de la licencia de uso y distribución Creative Commons Reconocimiento 4.0 Internacional (CC BY 4.0). 


\section{INTRODUCCIÓN}

Con la Segunda Ola Feminista (ca. 1960-1980), y particularmente durante la Tercera ( $c a$. 1990-actualidad), la crítica del uso androcéntrico y sexista del lenguaje irrumpía en escena. A pesar del rico y abundante material publicado desde entonces en lingüística feminista, por un lado, y en hermenéutica bíblica feminista, por otro, sorprende la escasez de obras que tratan la lengua hebrea bíblica desde una perspectiva de género. Mientras que la lingüística feminista ${ }^{1}$ ha profundizado en idiomas modernos (siendo su objetivo más sociopolítico que histórico), la hermenéutica bíblica feminista se ha concentrado, inter alia, en el análisis teológico ${ }^{2}$, literario ${ }^{3}$ e histórico ${ }^{4}$ del texto. El cruce de caminos entre

${ }^{1}$ Las dos principales preocupaciones de la lingüística feminista han sido, por un lado, la representación de la mujer en el lenguaje, abordándose ya sea desde el androcentrismo, ya desde el sexismo, y, por otro, la descripción de la comunicación lingüística diferencial de los individuos en función de su expresión e identificación de género en un contexto sociocultural determinado, para el cual se han acuñado los términos generolecto (del inglés genderlect) o sexolecto. Para una introducción a los postulados de la lingüística feminista, véase el ya clásico de Dale SPENDER, Man-Made Language (London: Routledge \& Kegan Paul, 1980). Para el caso del español, es de referencia obligada M. ángeles Calero Fernández, Sexismo lingüistico: análisis y propuestas ante la discriminación sexual en el lenguaje (Madrid: Narcea, 1999) y La percepción social de los sexolectos (Cádiz: Servicio de Publicaciones de la Universidad de Cádiz, 2007).

2 Véanse, a modo de ejemplos paradigmáticos, Phyllis Trible, God and the Rhetoric of Sexuality (Philadelphia 1978); Judith Plaskow, Standing Again at Sinai (New York: HarperOne, 1991), e Ivone Gebara, Teologia ecofeminista: esaio para repensar o conhecimento e a religião (São Paulo: Olho d'Água, 1997).

3 Phyllis TRIBLE, Texts of Terror: Literary-Feminist Readings of Biblical Narratives (Philadelphia: Fortress Press, 1984); Adela Y. Collins, Feminist Perspectives on Biblical Scholarship (Chicago: Scholar Press, 1984); Letty M. Russel, Feminist Interpretation of the Bible (Oxford: Blackwell, 1985); Athalya Brenner, Are We Amused? Humour about Women in the Biblical Worlds (London: T \& T Clark International, 2003). La aplicación de una teoría literario-feminista aparece encarnada en la colosal e interdisciplinaria serie de Athalya Brenner, Carole. R. Fontaine y Helen K. van WyK, (eds.), A Feminist Companion to the Bible (Sheffield: Sheffield Academic Press, 1993-2002 y 2015), seguida posteriormente por Amy-Jill Levine, A Feminist Companion to the New Testament and Early Christian Writings (Sheffield: Sheffield Academic Press, 2001-2010).

${ }^{4}$ Carol Meyers, Discovering Eve: Ancient Israelite Women in Context (New YorkOxford: Oxford University Press, 1988) y posteriormente, Rediscovering Eve: Ancient Israelite Women in Context (New York-Oxford: Oxford University Press, 2012); Erin 
ambas disciplinas se halla aún casi desierto, siendo escasas y muy recientes las voces que han optado por explorar esta interseccionalidad ${ }^{5}$.

Con la intención de contribuir a ese campo aún poco labrado y que promete ser fructífero, el presente artículo se adentra en las formulaciones hebreas bíblicas que describen $-\mathrm{y}$, por ende, prescriben- la naturaleza procreadora de lo femenino, en sus múltiples facetas y limitaciones. A través del análisis lexicológico y morfosintáctico de diversas formulaciones lingüísticas, el objetivo es realizar una radiografía sociolingüística de los discursos sobre la maternidad, su ausencia y las vías de solución ante dicha ausencia. Son estos tres temas, respectivamente, los que vertebran los epígrafes de este artículo.

Con el ánimo de permitir que el texto se interprete a sí mismo y explorar los obstáculos en el proceso de análisis semántico con los que toda lengua de corpus nos reta, se efectúa un rastreo de las raíces יל"ל עלכ"ד, שכ"ל y y la expresión idiomática יל"ד על ברכ" La metodología empleada es filológica, tomando como referente la primera regla de lo que se ha llegado a conocer como método Held: «special stress on disclosing the meaning of words by means of the inductive method rather that the use of the etymological one» ${ }^{6}$. Cuando el ítem léxico a analizar presente una baja frecuencia en el corpus, se descarta forzosamente la diacronía (v. gr. עק"ר). En otros casos, sin embargo, se puede efectuar un rastreo diacrónico (v. gr. יל"). Por otro lado, la metodología se inspira en el estudio de Kate Clark ${ }^{7}$, quien abordó la manipulación del

DARBY, Interpreting Judean Pillar Figurines: Gender and Empire in Judean Apotropaic Ritual (Tübingen: Mohr Siebeck, 2014).

${ }^{5}$ La única publicación que aborda la representación de las mujeres en la lengua hebrea es el trabajo diacrónico de Malka Muchnik, The Gender Challenge of Hebrew (Leiden: Brill, 2014). El estudio del generolecto en hebreo bíblico, efectuado a través del análisis de los diálogos en secciones narrativas, está siendo actualmente llevado a cabo en forma de tesis doctoral por Laura HARE, con título provisional Gendered Speech: A Sociolinguistic Study of Conversations between Men and Women in Biblical Narrative (University of Toronto).

${ }^{6}$ Chaim Cohen, «The "Held Method" for Comparative Semitic Philology», Journal of Ancient Near Estern Society 19 (1989) págs. 9-23: 10.

7 Kate Clark, «The Linguistics of Blame. Representations of Women in The Sun's Reporting of Crimes of Sexual Violence», en The Feminist Critique to Language, ed. Deborah CAMERON (London-New York: Routledge, 2005) págs. 183-197. 
lenguaje en la representación de las mujeres en incidentes de violencia de género y sexual en el tabloid británico The Sun durante la década de los ochenta. Su investigación se dividía en dos fases: un análisis sobre la nominalización (naming analysis), es decir, cómo se refería y describía a las mujeres, y un análisis sobre la gramaticalización (transitivity analysis), o sea, cómo funcionaban las oraciones en términos de agencialidad, proceso y objetivo. Aunque tanto el texto como el contexto del presente artículo difieren radicalmente del material con el que trabajó esta autora, el procedimiento de análisis lexicológico y morfosintáctico es extrapolable: se trata de una invitación a cuestionar y prestar especial atención al reparto de actantes masculinos y femeninos, ya sea en forma de presencia o ausencia, en determinadas construcciones lingüísticas. Por otro lado, también me remitiré a la semántica componencial para la clarificación de algunos términos semánticamente relacionados ${ }^{8}$.

De lo anterior se deriva que la perspectiva aplicada es de género. Ello implica un desplazamiento específico del foco de atención hacia la categoría sexo-género. A pesar de las sospechas por anacronismo que puede despertar este tipo de orientación en algunas disciplinas, la perspectiva de género, siendo una categoría analítica producto de una determinada sensibilidad moderna, no queda invalidada en función del objeto de estudio, sino que su valor es independiente de este. El límite lo establece el ejercicio de violencia interpretativa contra el espíritu original del texto, lo cual suele ocurrir precisamente en intentos eisegéticos de matriarcalización o, en otras palabras, de despatriarcalización, de un texto como el bíblico ${ }^{9}$. Todo artefacto cultural, a fortiori aquel que por sus coordenadas espaciotemporales no puede ser sino patriarcal ${ }^{10}$, es

${ }^{8}$ Se sigue la descomposición en semas propuesta por Jerrold J. KATz y Jerry A. FODOR («The Structure of Semantic Theory», Language 39 [1963] págs. 170-210).

9 De ello ha sido acusado el célebre opúsculo de Phyllis TriBLE, «Depatriarchalizing in Biblical Interpretation», Journal of American Academy of Religion 41:1 (1973) págs. 30-48. La respuesta a este artículo y, en general, a la obra de esta autora, entre otras que se sitúan en la misma línea, puede verse en David J. A. Clines, «Alleged Female Language about the Deity in the Hebrew Bible», sin publicar, pero accesible en: $<$ https://www.academia.edu/33883100/Alleged_Female_Language_about_the_Deity_ in_the_Hebrew_Bible.2> (último acceso: 04/10/2019)

10 Existen prácticamente tantas definiciones del término patriarcado como obras dedicadas al tema. Una sucinta definición meramente antropológica identificaría el pa- 
susceptible de ser leído a través de «unas gafas violetas», haciéndonos eco de la célebre metáfora acuñada por Gemma Lienas ${ }^{11}$.

Los pasajes bíblicos tratados son presentados en edición bilingüe hebreo-español. Con el objetivo de discutir cuestiones lexicológicas y presentar nuevas propuestas, las traducciones son siempre propias. Además, para presentar con transparencia algunas implicaciones gramaticales o semánticas, dichas traducciones son intencionalmente serviles al hebreo, aunque ello vaya en detrimento de la idiomaticidad del español.

¿Qué emociones personales y reacciones sociales despertaba la situación de una mujer que quería, y debía, ser madre? ¿Cuáles eran las diferentes maneras de anunciar un nacimiento y qué rol lingüístico jugaba la mujer (sujeto biológico) en la agencialidad? ¿Cómo se refería la lengua a quien sufría un aborto o no se quedaba embarazada? ¿Cómo se contrarrestaba la ausencia de prole con la primera esposa? El presente artículo pretende abrir la puerta a estos interrogantes, con la esperanza de poder ofrecer respuestas plausibles al final del camino, así como estimular la formulación de nuevas preguntas.

\section{LA MATERNIDAD EN EL ANTiguo IsRAEL}

El tercer capítulo de Génesis, un pasaje marcado por su omnipresencia simbólica y cultural, es un texto fatigado por la exégesis, y quizá por ello haya quedado cada vez más dificultada una disección de la narración con el juicio crítico, minucioso y sediento de quien se enfrenta por primera vez a una historia nueva. Para iniciar el análisis del rol de la mujer y la maternidad, valga recordar unos versículos de condena:

triarcado con «toda sociedad en la que los puestos claves de poder (político, económico, religioso y militar) están ocupados exclusiva o mayoritariamente por hombres»; cf. Alicia Puleo, Claves ecofeministas (Madrid: Plaza y Valdés, 2019) pág. 24.

11 Gemma Lienas, El diari lila de la Carlota (Barcelona: Empúries, 2001). 
14

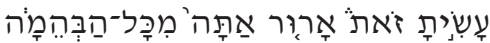

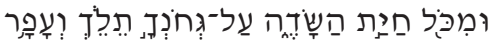

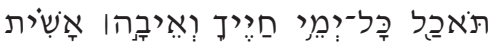

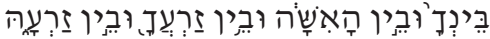

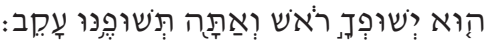

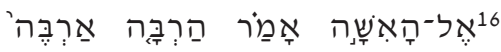

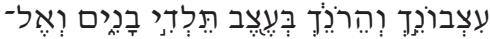

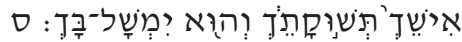

17

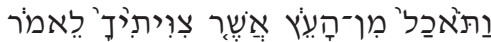

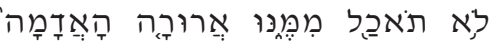

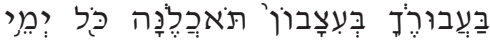

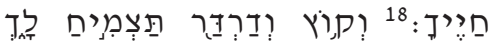

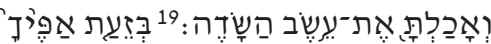

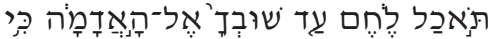

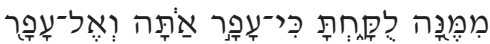

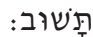

${ }^{14}$ Dijo YHWH 'Elohīm a la serpiente: «Puesto que has hecho esto, maldita seas entre las bestias y los animales del campo. Sobre tu vientre marcharás y polvo comerás todos los días de tu vida. ${ }^{15}$ Enemistad pondré entre tú y la mujer; entre tu descendencia y su descendencia. Esta te aplastará la cabeza y tú le morderás el talón».

${ }^{16} \mathrm{~A}$ la mujer le dijo: «Multiplicaré tremendamente tu sufrimiento y penuria; con dolor parirás hijos. Tu deseo será para tu marido y él te dominará».

${ }^{17}$ A Adán le dijo: «Puesto que has escuchado la voz de tu mujer y has comido del árbol del que te ordené no comer, maldita sea la tierra por tu causa. Con dolor comerás de ella todos los días de tu vida. ${ }^{18}$ Ella hará que te broten zarzas y espinas, y comerás la hierba del campo. ${ }^{19} \mathrm{Con}$ el sudor de tu frente comerás pan hasta que vuelvas a la tierra, puesto que de ellas has sido tomado. Polvo eres y al polvo volverás».

El relato es etiológico: da cuenta al mismo tiempo del sinuoso andar de la serpiente, del trabajo agrícola al que la subsistencia humana está sujeta, contrariamente a la del resto de animales (Sal 104:4) y del agudo dolor que provoca la vida que nace. Gen 3 habla de la transgresión del mandato divino, del ansia por el conocimiento connatural a la esencia humana y del castigo que racionaliza el porqué del ser de las cosas.

Estos versículos presentan una sistematización tripartita de los sujetos: animal (no humano) - (animal) humano masculino - (animal) humano femenino, que sobrevive hasta la actualidad. Por otro lado, hace 
patente una naturalización de lo femenino o feminización de la naturaleza plasmada en la interrelación entre las mujeres y la tierra ${ }^{12}$. Ambas son procreadoras y ambas son padecedoras o generadoras de sufrimiento:

12 Esta analogía, lugar común en sociedades agrícolas, ha sido ampliamente estudiada, y desde múltiples perspectivas. En el texto bíblico, las metáforas agrícolas sexuales pueden separarse temáticamente: la mujer como campo (Isa 49:21, si se da crédito a la etimología de גַלְמוֹדָ como 'tierra pedregosa' [ en árabe] de Marten Stol y F. A. M. Wiggermann, Birth in Babylonia and the Bible: Its Mediterranean Setting (Groningen: STYX Publications, 2000) pág. 2; Num 5:28; Cant 1:6; 4:12 y Sir 26:19-21); la mujer como planta (Lev 12:2 y Sal 127:3); la mujer como ganado (Jue 14:18, Amo 4:1 y 2Sam 12:2-4); invirtiendo el referente de la analogía, la tierra como mujer (Isa 55:10 y 2Re 2:19). Se habla de la mujer sin descendencia como tierra no labrada en Tel El-Amarna (EA 74:17-19): eqliyya aššata ša la muta mašil aššsum hali erêšim ('mi campo, por falta de arado, es como una mujer sin marido'). David Marcus, «A Famous Analogy in Rib-Haddi», Journal of Ancient Near Eastern Studies 5 (1973) págs. 281-286: 281. Se ha registrado un proverbio etíopico muy afín a esta idea, en Charlotte Leslau y Wolf Leslau, African Proverbs (Mount Vernon-New York, 1985) pág. 22. En árabe, es famosa la aleya coránica 2:223. Como contrapunto, se ha atestiguado la analogía entre el falo y el arado en acadio, en Claus WiLCKE, «A Riding Tooth: Metaphor, Metonymy and Synecdoche, Quick and Frozen in Everyday Language», en Figurative Language in the Ancient Near East, eds. M. MinduIn, Markham J. Geller y John E. Wansbrough (London: Taylor and Francis, 1987) págs. 69-92. Fuera de las lenguas semíticas, también el sumerio se hace eco de esta figuratividad: [sal-la]-mà ur $x_{x}-r u$ mu-lu-šà-ab-mà-kam ('¡Ara mi vulva, querido mío!'); cf. Samuel N. KRAmER, «Cuneiform Studies and the History of Literature: The Sumerian Sacred Marriage Texts», en Proceedings of the American Philosophical Society 107:6 (1963) págs. 485-527: 505-506. Especialmente revelador es el tecnicismo sáncrito para designar a la mujer del prójimo: para-kshétram, o 'campo ajeno'; cf. Vittore PisAnI, «La donna e la terra», Anthropos Bd. 37/40 H. 1/3 (1942/1945) págs. 241-253: 247. En Sófocles, los ejemplos son abundantes, pero basten dos ejemplos: para Edipo Rey 1255,

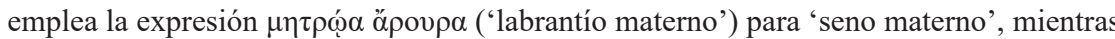
que en Antígona 569, Creonte le responde a Ísmene, cuando esta le increpa si es capaz

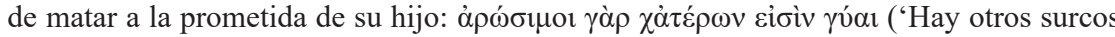
de arar'). En sintonía, Eurípides emplea $\pi \varepsilon \delta$ íov ('llanura') у $\lambda \varepsilon \mu \omega \omega ́ v$ ('pradera') para el cuerpo femenino; $c f$. Elizabeth CRAIK, «Sexual Imagery and Innuendo in Troades», en Euripides, Women and Sexuality, ed. Anton Powell (London-New York: Routledge, 1990) págs. 1-15. Otro estudio, también desde la filología clásica, es el de Page DuBLOIS, Sowing the Body: Pshycoanalysis and Ancient Representations of Women (Chicago: University of Chicago Press, 1991). La cuestión ha sido igualmente tratada desde la fenomenología de las religiones, como en Mircea Eliade, «La tierra, la mujer y la fecundidad», en Tratado de Historia de las Religiones vol. 2 (Madrid: Cristiandad, 1974) págs. 11-38, así como desde la antropología, donde sobresale el clásico de Sherry ORTNER, «Is Female to Male as Nature is to Culture?», en Feminist Studies 1:2 (1972) 
la mujer, en su función vital de reproductora, experimenta el dolor del parto para continuar la existencia de su especie, y la tierra, en su función vital de alimentadora, dificulta la cosecha de su propia descendencia, la cual perpetúa la vida humana en el mundo.

Uno de los detalles que la familiaridad con la que nos relacionamos con el texto puede haber nublado es la justificación del castigo. La divinidad maldice a la serpiente por haber hecho «esto», mientras que a Adán, por haber «escuchado» la voz de la mujer ${ }^{13}$. Eva, no obstante, esa bisagra literaria entre el victimario (la serpiente) y la víctima (Adán), y que es al mismo tiempo ambos, no recibe explicación alguna que legitime su castigo. No se le recrimina haber «escuchado a la serpiente», lo cual sin duda hizo, sino que se la castiga sin preludios.

Desde un punto de vista estructural, el orden de los castigos es directamente proporcional a la responsabilidad atribuida: la condena de la serpiente, cuya tentación desata la trama, es sucedida por la de Eva y esta por la de Adán. En el contexto narrativo inmediato, esta sucesión se construye quiásticamente con el diálogo anterior entre Dios y los personajes. En una sugerente descripción de cuán humana y atemporal es, ante el miedo, la defensa propia mediante delegación de responsabilidades, la divinidad cuestionaba primero a Adán, pero este culpaba a Eva, quien, a su vez, apuntaba a la serpiente. En lo que respecta al contenido, no se percibe, sin embargo, que la sucesión se corresponda con un incremento en la carga del castigo, sino más bien con una especialización de acuerdo a la naturaleza atribuida a cada individuo. Al dirigirse a la serpiente, la deidad se centra en su relación con el entorno físico, prescribiéndole cómo deberá trasladarse para la posteridad (ori-

págs. 5-31. Este ensayo será reivindicado retrospectivamente por el ecofeminismo como la principal contribución teórica a los postulados del movimiento.

13 En la primera mitad del siglo XIX, en una carta que la cuáquera Sarah Grimké escribía a Mary Parker, presidenta de la Sociedad Femenina Abolicionista de Boston, esta arroja una original interpretación sobre por qué la transgresión de Eva es cualitativamente distinta a la de Adán, invirtiendo la exégesis tradicional: «Here the woman was exposed to temptation from a being with whom she was unacquainted. [...] We next find Adam involved in the same sin, not through the instrumentality of a supernatural agent, but through that of his equal, a being whom he must have known was liable to transgress the divine command [...]»; cf. Sarah GRImkÉ, Letters on the Equality of the Sexes and the Condition of Women (Boston: I. Knapp, 1838) pág. 6. 
ginalmente, la serpiente tendría patas) y cómo se truncará en enemistad su interacción con el entorno humano. Al dirigirse a la mujer, se refiere igualmente a su corporalidad, específicamente en lo que respecta a su capacidad procreadora y a la nueva condición servil a la que somete su sexualidad. La serpiente y Eva son percibidas como seres primariamente materiales, pero no así Adán. Cuando la divinidad se dirige a este, reconoce en él a un ser también sujeto a la materialidad, pero aún así diferente. Él adquiere una dimensión cultural (trabajo) y temporal: Adán tiene pasado (era polvo), presente (está vivo) y futuro (volverá al polvo). La mujer, no obstante, no es enmarcada en ninguna dimensión si no es con respecto a su función social (descendencia) o autoridad (marido). Recordemos que ella no es polvo, sino costilla.

Algunos estudios de literatura comparada han propuesto decodificar el castigo de Eva como contrapunto de los partos indoloros de las diosas de la mitología mesopotámica ${ }^{14}$. En el siglo XIX, en el momento en que la medicina experimentaba con la anestesia, la lección bíblica «parirás con dolor» (Gen 3:16) servía de argumento contra su empleo en parturientas ${ }^{15}$, en un ejercicio del hombre (masculino no neutro) como custodio y ejecutor de la voluntad divina.

La mortalidad maternal, que sin duda debió haber alcanzado altos porcentajes en época israelita, está pobremente reflejada en el corpus bíblico. El ejemplo por excelencia es la historia de Raquel. Cuando ella agoniza en su segundo y último parto, las palabras de consuelo que la partera le dirige nos enfrentan con una sociedad en la que no solo la maternidad se comprende como la función vital femenina, sino que engendrar varones es lo que convierte a las mujeres en merecedoras de honor: «Ocurrió que, cuando se le complicaba el parto, la partera le dijo: No temas, puesto que te ha sido niño» (Gen 35:17). El texto murmura que los partos pueden ser mortales, pero no por ello infelices.

Preguntamos aquí lo siguiente: ¿cómo se describen oracionalmente los partos en el corpus bíblico? Si estudiamos los procesos de nominalización (cómo se refiere y describe al sujeto femenino en la oración) y

14 Adrien J. Bledstein, «Was Eve Cursed?», Bible Review 9:1 (1993) págs. 42-45.

15 Peter M. DunN, «The Holy Bible: insights into perinatal practice in ancient times», en Archives of Disease in Childhood Fetal and Neonatal 75:3 (1996) págs. 219220: 220.

SEFARAD, vol. 79:2, julio-diciembre 2019, págs. 323-355. ISSN: 0037-0894. https://doi.org/10.3989/sefarad.019-009 
de gramaticalización (cómo funcionan las oraciones en términos de agencialidad, objetos y procesos), podremos adentrarnos en cómo se concebía el rol femenino -y, en paralelo, el masculino- en el fenómeno reproductivo. Con este objetivo, se analizan morfosintácticamente una serie de construcciones dadas en hebreo bíblico para describir el nacimiento de un bebé y que, mientras significan lo mismo (a saber, ' $\mathrm{X}$ nace'), se construyen de forma muy diversa. Este grupo de construcciones serán referidas en adelante como «expresiones de natividad». Precisamente por este motivo, se excluye un estudio pormenorizado de la raíz , הר"ה, puesto que el análisis se circunscribe al nacimiento, no a la gestación. Para evitar ambigüedades en la traducción, el verbo aparecerá en subrayado, el complemento directo en itálicas y el complemento indirecto en negrita.

La primera expresión de natividad (a) contiene secuencialmente, en construcción idiomática, las raíces hebreas הר"ד y ('concebir') הר"ה ('parir') con un sujeto femenino:

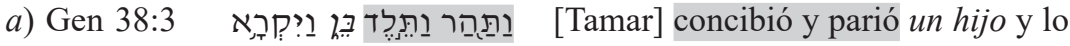

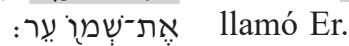

Una manera más concisa de expresar esta misma idea es prescindiendo de la raíz הר"ה y manteniendo a la mujer como sujeto. Esta construcción se presta a cierta variación sintáctica, ya que puede presentar (c, d) o no (b) un dativus commodi. En el caso de que haya, este siempre remite al padre de la criatura ${ }^{16}$. En estos ejemplos, las mujeres paren, pero los hombres continúan siendo el punto de referencia del nacimiento, porque la acción revierte directamente sobre ellos:
b) Gen 30:21

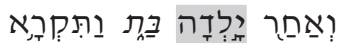

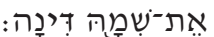
Después, [Lea] parió una hija y
la llamó Dina.
c) Gen $34: 1$

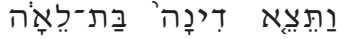

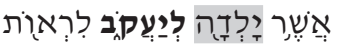

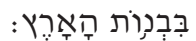
Salió Dina, la hija de Lea, quien
se [la] había parido a Jacob, a
ver a las hijas del país.

${ }^{16}$ El caso de Rut 4:17 difiere de los presentados, siendo el dativus commodi es una mujer (Noemí). El pasaje ha sido interpretado en término adoptivos. 
d) Gen $44: 27$

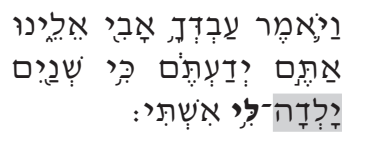

Nos dijo tu siervo, nuestro padre [Jacob]: «Sabéis que dos veces me ha parido mi mujer [Raquel]»

Especialmente interesantes son las expresiones de natividad en las que la mujer, agente real del verbo, desaparece de la escena oracional. La primera construcción (e, f) es una oración pasiva en la que el bebé es el sujeto paciente y el padre continúa como dativus commodi. Las traducciones por 'a $\mathrm{X}$ le nació $\mathrm{Y}$ ' son idiomáticas en español, pero emborronan el espíritu hebreo, donde el acto de «nacer» no se expresa en términos activos, sino pasivos ${ }^{17}$. El foco de la acción se traslada del ser que pare al ser parido y al ser a quien beneficia tal nacimiento:
e) Gen 10:1

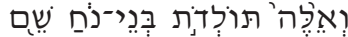
Esta es la genealogía de los hijos

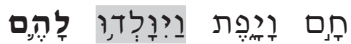

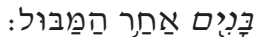 de Noé: Sem, Cam y Jafet. Les fueron paridos hijos después del Diluvio.

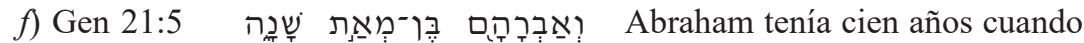 : le fue parido Isaac, su hijo.

Mientras que (e) no presenta irregularidades sintácticas, (f) incorpora una nota accusativi para indicar el sujeto, lo cual no es imposible en

\footnotetext{
17 El verbo hebreo se conjuga en qal pasivo en el texto consonántico, pero es reinterpretado como nif'al por la vocalización masorética siempre y cuando sea posible, es

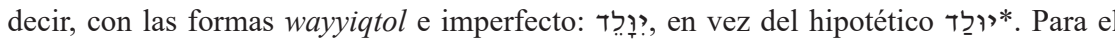
perfecto, donde nif'al no es ortográficamente posible, se vocaliza como pu 'al: ‘ ?י, en

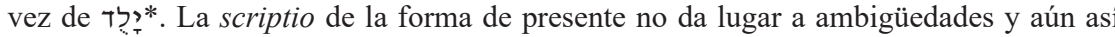

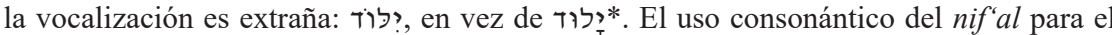
infinitivo se explica porque qal pasivo carece de flexión para el infinitivo, en cuyo caso nif'al adquiere un rol supletorio. La interpretación masorética de la raíz como pu'al y nif'al, dependiendo del tiempo verbal, parece influida por la pronta pérdida del qal pasivo y el consecuente triunfo del nif'al, que ya se aprecia en hebreo bíblico tardío, como se atestigua en Crónicas (נולד). Una explicación detallada se encuentra en Paul JoüON, «Études de morphologie hebraïque», Biblica 1 (1920) págs. 359-361. Para un tratamiento de evoluciones gramaticales análogas, véase Geoffrey KHAN, «Biblical Hebrew: Linguistic Background of Masoretic Text», en Encyclopedia of Hebrew Language and Linguistics, ed. Geoffrey KHAN (Leiden: Brill, 2013) págs. 304-314.
} 
hebreo bíblico, pero sí extremadamente inusual ${ }^{18}$. Cabe matizar, ante el silencio académico sobre esta cuestión, que dicha irregularidad es regular en las expresiones de natividad en las que יל"ד se emplea en pasiva. Énfasis es la explicación más recurrente, pero Geoffrey Khan ha propuesto una ergatividad sui géneris en la que, por ende, la alineación establecida no es agente-sujeto, sino objeto-sujeto:

Constructions with 'et before the subject in Biblical Hebrew can be neatly explained as being clauses which evidence traces of 'active'-type (quasi-ergative) morphology. This is demonstrated by the fact that in nearly all instances 'et co-occurs with intransitive subjects [...], all of which are to be construed as non-volitional ${ }^{19}$.

Según dicha explicación, en esta expresión de natividad con nota accusativi, el sujeto sería sentido por el hablante como objeto porque, a pesar de la pasividad morfológica, los bebés en hebreo no ejecutan la acción de «nacer», sino que «alguien los pare».

La madre puede aparecer, aunque minoritariamente, precededida de la preposición -מ. Este tipo de construcción se encuentra, desde un punto de vista de la gramaticalización, a medio camino entre la enunciación activa y la pasiva: la mujer, cuya agencialidad es implícita, es referida como complemento agente. No obstante, su mención obecede a motivos de claridad narrativa: ( $g$ ) especifica quién fue la madre de Er, Onán y Shela solo porque tiene que diferenciarlos de aquellos que Judá tuvo con Tamar, mencionados en el versículo inmediatamente posterior (h), donde se hacía uso de una construcción activa vista arriba. Obsérvese el uso de la ruptura sintáctica con waw-X-qatal ${ }^{20}$, que acentúa el contraste:

18 Para una clasificación de los usos en los que את no acompaña a un objeto directo, véase Paul Joüon y Takamitsu Muraoka, Gramática del hebreo bíblico (Navarra: Editorial Verbo Divino, 2007) págs. 470-471.

19 Geoffrey Khan, «Object Markers and Agreement Pronouns in Semitic Languages», Bulletin of the School of Oriental and African Studies 47:3 (1984) págs. 468-500: 496-497.

20 Para una introducción a la sintaxis textual, véase Alviero NicCACCI, Sintaxis del hebreo bíblico (Navarra: Editorial Verbo Divino, 2002). 
g) 1 Cro $2: 3 \mathrm{a}$

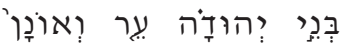

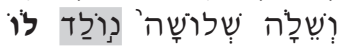

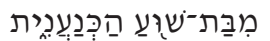

h) 1 Cro $2: 4$

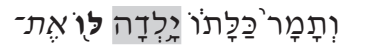

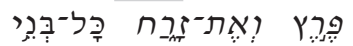

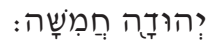

Los hijos de Judá fueron 'Er, 'Onán y Shela. Tres le nacieron de Bat-Shu'a, la cananea.

Mientras que Tamar, su nuera, le parió a Peres y a Zéraj. Cinco fueron todos los hijos de Judá.

El cuarto y último lugar lo ocupa una expresión de natividad en la que el sujeto es masculino, con o sin objeto directo. El verbo empleado es יל'ד en qal o en hif'il. Ronald Hendel ha estudiado la evolución semántica de esta raíz y concluido que ya en tiempos bíblicos se generó una diferenciación gramatical en función del sexo del sujeto ${ }^{21}$. En los sustratos más antiguos del hebreo, qal habría sido empleado indistintamente del sexo del sujeto. Así, הר"ה era a יל"ד lo que «concebir»a «engendrar»: la diferencia semántica la marcaría el sexo del sujeto, en función de sus particularidades biológicas. Con el tiempo, la raíz יל"ד desarrollaría una conjugación homóloga especializada en sujetos masculinos. De esta forma, permanecía el uso del verbo conjugado en qal si el sujeto era una mujer ('parir'), pero se pasaba a utilizar hif'il si el sujeto era un varón ('hacer parir', en el sentido de 'procrear', pero se mantiene la traducción primera porque refleja mejor la causatividad que subyace a la evolución). La ausencia de la parte femenina en esta expresión de natividad $(i, j)$ delata un tono patriarcal que coquetea con visiones partenogenéticas en la que el rol de las mujeres se pasa por alto en el acto comunicativo:

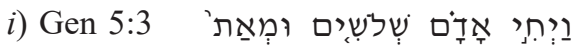

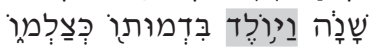

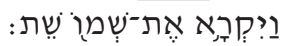
Adán tenía ciento treinta años cuando hizo parir a su imagen y semejanza. Lo llamó Set.
j) Gen 5:6

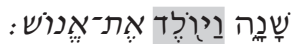

${ }^{21}$ Ronald Hendel, «"Begetting" and "Being Born" in the Pentateuch: Notes on Historical Linguistics and Source Criticism», Vetus Testamentum 50:1 (2000) págs. 3846. Tanto las motivaciones como los objetivos del autor se circunscriben al ámbito de la crítica textual y literaria, pero sus resultados son especialmente sugerentes para análisis gramaticales con perspectiva de género. 
A modo de recapitulación, la siguiente tabla recoge las estructuras morfosintácticas analizadas. Se incorporan llaves para señalar el carácter optativo del elemento, los símbolos $q$ y $\widehat{o}$ para explicitar el sexo del actante y $\sqrt{ }$ para la descendencia, como guiño al término

$$
\begin{aligned}
& \text { 1 } \\
& \text { 2 } \\
& \text { 3. } \\
& \text { 4. } \\
& \text { V }
\end{aligned}
$$

En el Antiguo Israel, parir hijos al marido se consideraba una victoria femenina. En modalidades bígamas del matrimonio, lo era especialmente para la mujer no favorita. Se comprueba que, en los dos relatos que mejor tratan el tema de la competición entre esposas (Raquel-Lea en Gen 29 y Ana-? en 1Sam 2), el marido siempre mantiene su preferencia por la mujer sin prole que está afligida, quien se enfrenta al desprecio de la coesposa o rival (צרה), descrita como procreadora exitosa. Ante la ausencia de prole, los relatos se centran en la envidia y enemistad femeninas, pero resaltan la compasión del hombre; o quizá su incomprensión. Cuando el marido de Ana le pregunta por qué llora y ha dejado de comer, añade: «iAcaso yo no soy para ti mejor que diez hijos?» (1Sam 1:8). El autor bíblico lo retrata como un marido tierno, pero una lectura con perspectiva de género decodifica estas palabras como las de un hombre ajeno a la opresión femenina en la que coparticipa. Él siempre tendrá los hijos de su otra mujer, pero no así Ana, quien habita un mundo en el que la maternidad define la razón de ser femenina.

\section{LA AUSENCIA DE MATERNIDAD EN EL ANTIGUO ISRAEL}

El pasaje de Ana formula nuevas preguntas: ¿cómo se expresaba en hebreo la ausencia de maternidad? ¿Cómo se llamaba a la mujer que,

${ }^{22}$ Véase el epígrafe siguiente. 
siendo sexualmente madura y formando matrimonio, no tenía embarazos? ¿Dejaban de ser madres aquellas que sí lograban concebir, pero sufrían abortos?

El significado básico de la raíz hebrea שכ"ל está relacionado con la privación de descendencia, entendiéndola no como ausencia $a b$ initio, sino como el arrebatamiento de la prole ya nacida. En forma de adjetivo pasivo, la palabra שכול califica a un sujeto animal ${ }^{23}$. De las siete veces que aparece atestiguado en el corpus bíblico, dos se refieren a los rebaños (Cant 4:2; 6:6) y tres a los osos (2Sa 17:18; Os 13:8 y Pro 17:12), estos últimos como símbolo de extremo peligro. Sorprende su poca frecuencia con sujetos humanos. Los dos únicos casos (Isa 49:21 y Jer 18:21a) califican a mujeres azotadas por el horror de la batalla:

k) Jer 18:21a

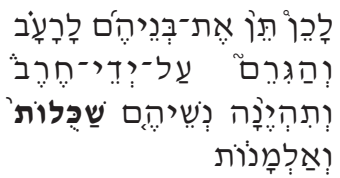

Por ello, entrega a sus hijos al hambre y masácralos por medio de la espada. Se conviertan sus mujeres en šakkulōt y viudas.

En su forma verbal, la raíz se emplea para hablar del estado (en qal) y la acción (en $p i^{\prime} e l$ ) por la que se padece o causa la muerte de algún hijo o hija, respectivamente. Con las siguientes palabras asesina el profeta Samuel a Agag, rey de los amalequitas:

l) $1 \mathrm{Sam} 15: 33 \mathrm{a}$
Dijo Samuel: "Así como tu espada ha privado a [muchas] mujeres [de descendencia], así también quede privada [de ti] tu madre entre las mujeres».

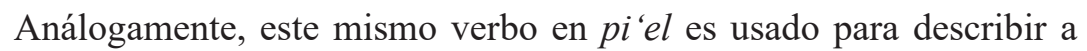
hembras que sufren abortos espontáneos ${ }^{24}$. Mientras que el hebreo no

23 Carecemos en castellano contemporáneo de un equivalente que traduzca el término hebreo. Aunque la palabra huérfano aparece recogida en el DLE con una segunda acepción de 'persona a quien se le han muertos los hijos', su uso es poético, por lo que en adelante emplearé, sin traducir, el término hebreo transcrito a caracteres latinos.

24 Se desconoce si existió un término para diferenciar al aborto espontáneo del inducido, puesto que la ley israelita no menciona prácticas abortivas, sino solo acci- 
entiende el nacimiento como un acción, sí concibe así el aborto. Lo opuesto ocurre en español, donde la manera que tenemos de hablar de esta circunstancia implica ver al sujeto como paciente («sufrir un aborto» como circunstancia, opuesto a «abortar» como acción). En la morfosintaxis hebrea, la mujer ejecuta la acción: no «sufre» un aborto, sino que «priva de descendencia» (se entiende) a sí misma y su marido. Sirva como ilustración una promesa de bonanza y prosperidad con la que Dios bendice al pueblo israelita en su vagar por el desierto:

m) Ex 23:26

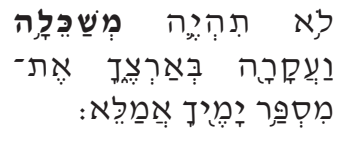

No habrá abortiva ('quien prive de descendencia') ni 'aqarâ ${ }^{25}$ en tu tierra. Llenaré el número de tus días.

Conviene matizar que otros argumentos también actúan de sujeto para este verbo: las espadas son «privadoras de descendencia» (Deut 32:25; 1Sam 15:33 y Lam 1:20), así como lo es el hambre (Eze 5:17) o incluso la tierra, cuando no crece en ella la semilla sembrada (2Re 2:19.01 y Mal 3:11).

En hif'il, el verbo solo está registrado en una ocasión (Os 9:14), donde el profeta prescribe el castigo por los pecados de Israel. Si la divinidad bendecía con descendencia (m), maldecirá con embarazos fallidos y maternidad frustrada (n). Obsérvese el sujeto, esta vez el vientre:

dentes (Ex 21:22). Este silencio legal es especialmente intrigante si se compara con la regulación minuciosa que la práctica recibió en códigos legales del Próximo Oriente Antiguo. En el Código Asirio Medio, la ley 53 de la Tablilla A estipula que la mujer acusada de abortar debía ser condenada a empalamiento: viva, si había sobrevivido a la operación, o muerta, si hubiera habido complicaciones. Además, se prohibía la posterior inhumación de su cadáver como endurecimiento de su humillación pública. Véase Godfrey R. Driver y John C. Miles, The Assyrian Laws (Germany: Scientia Verlag Aalen, 1975) pág. 421. En hebreo moderno, הפלה se refiere indistintamente al aborto espontáneo y al inducido. A nivel nominal, ocurre lo mismo en español (donde hemos de recurrir a la adjetivación para especificar el tipo de aborto), pero hay una clara diferenciación en otras lenguas, como por ejemplo en inglés (miscarriage versus abortion), alemán (Fehlgeburt versus Abtreibung) o francés (fausse couche versus avortement).

25 Este término se deja aquí simplemente transcrito, pues es debatido a continuación. 
n) Os 9:14

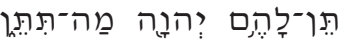

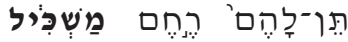

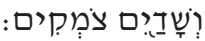

Darles, YHWH, ¿qué [les] darás? ¡Dales un vientre abortivo [i.e. 'que [las] convierta en šakkulōt] y unos pechos secos! $!^{26}$

Una vez analizada la representación lingüística de la privación de descendencia, conviene analizar la de su ausencia ab initio. El hilo narrativo del libro de Génesis cose las tres grandes historias de AbrahamSara, Isaac-Rebeca y Jacob-Raquel a través del leitmotiv de la esterilidad. «Estéril» o «infértil» es el término por el que las traducciones de la Biblia al español vierten, con absoluta unanimidad, el adjetivo femenino עקרה.

Este vocablo aparece un total de doce veces en el corpus bíblico ${ }^{27}$, y solo en una ocasión se refiere a un sujeto masculino (Deut 7:14). Las traducciones de la Biblia al español se enfrentan a este presunto reto de género de formas diversas, pero desde el mismo punto de partida. Lo ilustran cuatro traducciones procedentes de las designaciones religiosas más representantivas en nuestra sociedad: la Reina Valera Actualizada 2006 (RVA), evangélica; la Sagrada Biblia de Cantera e Iglesias (CI), católica y filológicamente muy preciada; la Traducción del Nuevo Mundo de las Sagradas Escrituras (TNM), por los Testigos de Jehová; y La Biblia del Peregrino (PER), traducción a cargo del poeta jesuíta y biblista Luis Alonso Schökel. Todas ellas dan el valor de 'estéril' para el adjetivo en las diez ocasiones que aparece aislado en femenino, pero algunas cambian de criterio cuando traducen su homólogo masculino:

${ }^{26}$ Hay quienes han entendido este versículo como una doble mención: al aborto (רחם משכיל) y a la infertilidad (שדים צמקים). La segunda expresión, no obstante, debe entenderse como una consecuencia de la primera: la mujer que ha sufrido un aborto, y por ende no ha llegado al parto, no produce leche. La referencia es a la experiencia de la mujer embarazada que aborta y que no llega a dar de mamar, no a quien ni siquiera ha concebido. Véase Stol y Wiggermann, Birth in Babylonia and the Bible.

27 Gen 11:30; 25:21; 29:31, Ex 23:26, Deut 7:14 (x2), Jue 13:2.3, 1Sam 2:5, Job 24:21, Sal $113: 9$ e Isa 54:1. 


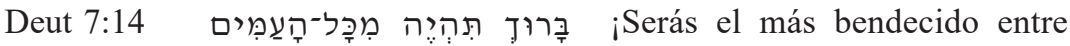

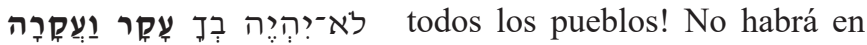

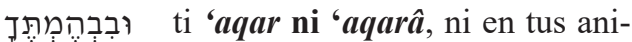
males de ganado.

TNM Llegarás a ser el más bendito de todos los pueblos. No resultará haber en ti macho ni hembra sin prole, ni entre tus animales domésticos.

CI ¡Bendito serás entre todos los pueblos! No habrá en ti varón ni hembra estéril, ni en tus ganados.

RVA Serás más bendecido que todos los pueblos; no habrá hombres ni mujeres estériles en medio de ti, ni entre tus animales.

PER Serás bendito entre todos los pueblos; no habrá estéril ni impotente entre los tuyos ni en tu ganado.

CI y RVA mantienen una equivalencia absoluta. Sin embargo, PER interpreta la forma masculina del adjetivo como un dual aparente: un término que significa $\mathrm{X}$ si se refiere a un ente femenino, pero $\mathrm{Y}$ si es masculino ${ }^{28}$. Así, se toma עקרה por 'estéril', pero עקר por 'impotente'. ¿Cuál es la evidencia textual para tal decisión traductológica?

La traducción de PER es cuestionable especialmente si tenemos en cuenta que, en su diccionario de hebreo bíblico, Schökel solo da dos valores para este lema: «estéril, infecundo», sin mención alguna de «impotente» ${ }^{29}$. La dualidad percibida de la que se hace eco PER se retrotrae hasta el siglo III a.e.c., pues así también pareció entenderlo la Septuaginta. La traducción griega de Deut 7:14 empleaba para עקרה el

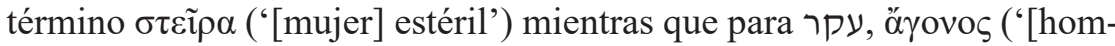
bre] sin prole'). La diferencia semántica entre ambos es, respectivamente, la misma que hay entre la imposibilidad y la contingencia.

En lo que respecta a la tradución por la que opta TNM, sorprende que la presencia del adjetivo masculino influya en el significado del femenino: ahora el lexema significa 'sin prole', contrariamente a los

28 Sobre los duales aparentes, véase M. ${ }^{a}$ Ángeles CALERo FernándEZ, «La relación género gramatical-sexo biológico desde Nebrija hasta 1771», en Nebrija V centenario: actas del Congreso Internacional de Historiografía Lingüistica 3 (1994) págs. 121-140.

29 Luis A. SchöKel, Diccionario bíblico hebreo-español (Madrid: Trotta, 2014) pág. 585 . 
once casos femeninos donde esta traducción lo entiende sistemáticamente como 'estéril'. La decisión traductológica de la TNM no puede explicarse sino como injerencia de una agenda política con marcados prejuicios sexistas.

Como estos ejemplos ilustran, reina cierta fluctuación: el adjetivo se toma a veces como 'estéril' y otras como 'sin prole'. La incoherencia puede darse incluso en líneas consecutivas:

This adj primarily describes a mature, married woman, who has not born any children. It does not necessarily mean that such a woman believed that she was incapable of ever having children [...] In Dt 7.14 עק is descriptive of a man, giving evidence that there was some recognition of male sterility in ancient Israel $^{30}$.

Se han manifestado posicionamientos alternativos con respecto a la semántica de este adjetivo, aunque no son numerosos ni detallados en su argumentación. Moshe Caspi explicaba a la mujer 'aqarâ no como estéril, sino como quien padece una enfermedad (sic) recurrente en la Antigüedad y que azotaba especialmente a las pastoras de tribus nómadas. Apelaba a la etimología, siendo 'arrancar' uno de los valores de la raíz עק", para señalar que término significaba originariamente 'abortiva':

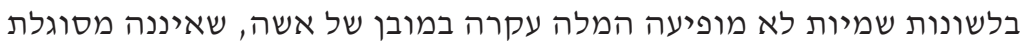

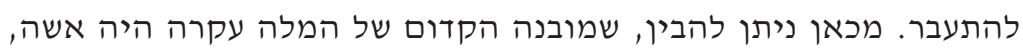

שעוברה נעקר, דהיינו נעקר שורשה ניתמבתה 31

Aunque la discusión etimología pueda arrojar cierta luz, su explicación no funciona en un contexto sincrónico porque deriva en un nuevo problema para traducir el masculino en Deut 7:14. Independientemente

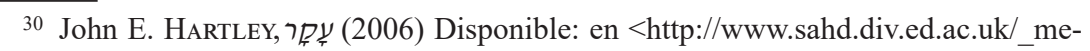
dia/lexeme:pdf:jtw-aqar-hartley_j-azu-2006p.pdf> [última consulta: 04/10/2019]. La entrada pertenece al proyecto lexicográfico internacional Semantics of Ancient Hebrew Database, aún en construcción.

31 Traducción de la cita: 'En las lenguas semíticas, no aparece la palabra 'aqarâ con el sentido de mujer que no es capaz de quedarse embarazada. De ahí se entiende que el sentido primigenio de la palabra era el de una mujer cuyo feto se ha arrancado; es decir, cuya raíz se ha arrancado'. Moshe CASPI, מושיבי עקרת הבית אם הבנים שמחה", Beit Mikra: Journal for the Study of the Bible and Its World 25:4 (1980) págs. 365-366: 366. 
de cuál sea la semántica originaria del término, el significado de 'mujer abortiva' es una conjetura puramente etimológica y carece de soporte textual dentro del corpus bíblico.

Como ejemplo de la incomodidad que despertó esta presunta mención de la esterilidad masculina en Deut 7:14, vemos que Pietru Saydon propuso que la forma masculina no tenía sentido semántico real, sino que se trataba de un recurso retórico, por paronomasia, que enfatizaba la promesa de desterrar la esterilidad (femenina) de Israel ${ }^{32}$. Apoyaba su tesis en el versículo de Isa 3:1, en el que se varía el género de un sus-

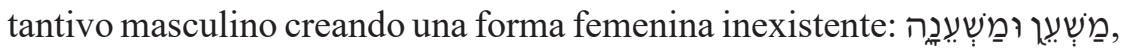
'sustento y sustenta', es decir: 'todo sustento'.

La explicación de Saydon se presta a varias críticas. En primer lugar, hay un problema metodológico por el cual el autor parte de la premisa de que lo excepcional en el corpus necesita ser explicado como recurso retórico, cuando podría explicarse por aletoriedad evidencial. En otras palabras: el hebreo bíblico (como lengua de corpus) no se corresponde con el hebreo antiguo (como lengua vernácula) ${ }^{33}$. Secundariamente, Saydon pasa por alto que el adjetivo masculino עקר sí existe en hebreo postbíblico (de mishnaico en adelante). Aunque eso no justifique la extrapolación del significado de un estrato a otro, sí debilita la hipótesis de que la forma masculina sea una anomalía lingüística. En tercer lugar, el lenguaje de Isaías es poético, con las licencias estilísticas que ello le permite, mientras que no así el del fragmento de Deuteronomio. Por

32 Pietru P. SAYdon, «Assonance in Hebrew as a Means of Expressing Emphasis», Biblica 36:1 (1955) págs. 36-50.

33 Contrastando los adjetivos bíblico y vernáculo, señalo la necesidad de explicitar que un corpus limitado como lo es la Biblia Hebrea es incapaz de reflejar al completo la lengua diaria de los hablantes contemporáneos. Véase Edward UlLENDORFF, «Is Biblical Hebrew a Language?», Bulletin of the School of Oriental and African Studies 34:2 (1971) págs. 241-255. Recientemente se han establecido otros criterios para la adjetivación del hebreo antiguo, como por ejemplo la distinción entre «hebreo bíblico» $\mathrm{y}$ «hebreo clásico», tal y como aparece propuesto en el último y más exhaustivo proyecto lexicográfico: «[u]nlike all previous dictionaries of ancient Hebrew, this work does not restrict itself to, or privilege in any way, those ancient Hebrew texts found in the Hebrew Bible. Rather, it views Hebrew simply as a language like any other ancient language, for which it is necessary to examine the evidence of all the extant texts», en David J. A. CLINES, (ed.), The Dictionary of Classical Hebrew (Sheffield: Sheffield Academic Press, 1993) pág. 7. 
último, la comparación entre Isa 3:1 y Deut 7:14 resulta falaz porque, en el primer caso, se trata de un sustantivo, mientras que en el segundo, de un adjetivo. El género de ciertos sustantivos como משען no puede modificarse libremente sin que ello atente contra las normas internas de la gramática. Pero no ocurre así con los adjetivos, excepto si ello atenta contra las normas internas de la biología. En efecto, rápido se percibe que el debate académico orbita alrededor de esa pregunta: ¿es posible que se concibiera en el Antiguo Israel la esterilidad masculina, o más bien se entendía como inhabilidad específicamente femenina? La hipótesis que plantea esta sección del artículo pretende responder a un interrogante más general: ¿se concebía en el Antiguo Israel la esterilidad?

Son escasas las voces que se han opuesto a una traducción por 'estéril'. Así John Van Seters ${ }^{34}$, cuyo posicionamiento se refleja únicamente en su traducción al inglés (childless, en lugar de barren) y Nahum Sarna, en cuyo comentario a Génesis menciona: «Hebrew 'akarah simply means "childless" but not necessarily infertile» ${ }^{35}$. Desafortunadamente, ningún autor profundiza en sus propuestas.

Siguiendo el método Held ya citado, la clave para comprender la semántica del adjetivo debería buscarse primeramente no en la etimología (Caspi) ni en la asunción de que operan recursos literarios (Saydon), sino en la evidencia interna, dejando que el texto se interrogue y conteste a sí mismo a través del resto de apariciones en el corpus. Si se analizan estas doce ocasiones, en cinco de los versículos aparece acompañado por la raíz יל" más un elemento de negación. Las expresiones son: «adje-

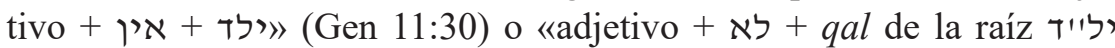
conjugada» (Jue 13:2.3; Job 24:21 e Isa 54:1). Los cuatro casos son ambiguos, porque «no haber parido» puede explicar ser 'aqarâ de varias formas. El primer caso, no obstante, es iluminador. Véase el adjetivo en cursiva y la perífrasis negativa en negrita:

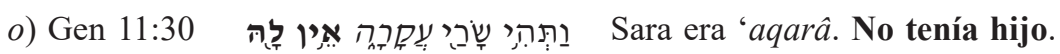

34 John VAn Seters, «The Problem of Childlessness in near Eastern Law and the Patriarchs of Israel», Journal of Biblical Literature 87:4 (1968) págs. 401-408.

35 Nahum M. SARna, Genesis (Philadelphia: Jewish Publication Society, 1989) pág. 87.

SEFARAD, vol. 79:2, julio-diciembre 2019, págs. 323-355. ISSN: 0037-0894. https://doi.org/10.3989/sefarad.019-009 
Compárense ahora (o) y (p), tomado de un contexto literario distinto. Ambas formulaciones presentan la misma estructura sintáctica: «adjetivo + אין + perífrasis». Además de la similitud sintáctica, son comparables semánticamente porque describen a la descendencia y/o su falta:

p) Jue 11:34
Llegó Jefté a Mizpá, a su casa, y he aquí que su hija salía hacia él con tambores y danzas. Era [hija] única. No tenía aparte hijo o hija.

אוֹ־ַת:

Este tipo de secuencia sintáctica también aparece en contextos no relacionados con la $\mathrm{m} /$ paternidad:

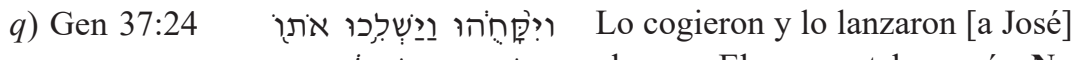

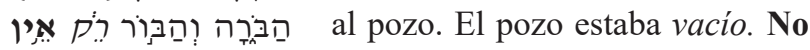
בוֹ מָיִם:

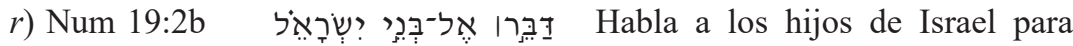

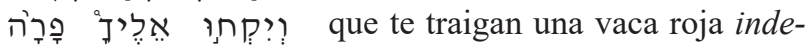
fectuosa, en la que no haya de-

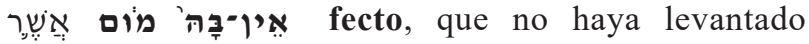

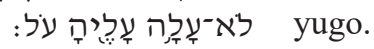

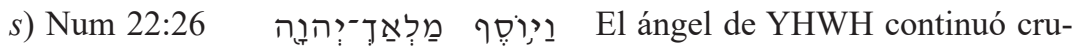

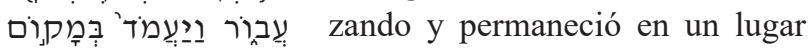

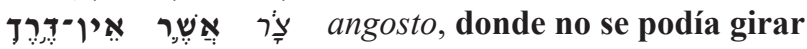

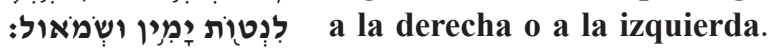

En estos ejemplos, la perifrásis constituye una explicación en negativo del adjetivo (q), que puede realizarse de manera pleonástica con una forma cognada (r) o a través de una descripción más elaborada de las implicaciones del adjetivo (s). En efecto, «vacío» y «sin agua» son sinónimos en lo que respecta a un pozo (q); ser indefectuoso implica lógicamente carecer de defecto (r); y los lugares angostos lo son al impedir moverse cómodamente en su interior (s).

אין + A la luz de estos fragmentos, la secuencia sintáctica «adjetivo + perífrasis» adquiere un valor tautológico y enfático por el se describe dos veces el mismo fenómeno. La segunda vez que se hace, con la pe- 
rífrasis, se habla del resultado. Aquí resulta crucial diferenciar entre resultado y causa. Si estas oraciones hablaran de causa, por ejemplo para (q), se alegaría la escasez de lluvia (לא המטיר בארץ*), que explicaría la condición del pozo. El texto, no obstante, decide hacer hincapié en la descripción del pozo: ¿cuál es el resultado de que esté vacío? No hay agua que sacar.

Considero que es este tipo de perífrasis en la que se inserta אין la clave para comprender la semántica del adjetivo que la precede. A la luz de estos pasajes y Gen 11:30, 'aqarâ debe entenderse en sintonía con la expresión que le sucede: no como 'estéril' (que sería la causa), sino como 'mujer sin descendencia' (que es el resultado).

La etimología del término עקר/ה, que no ha de desatenderse, debería sin embargo constituir la última fase en el proceso de análisis. La vasta envergadura semántica de la raíz semítica עק" acoge, en sus formas verbales y nominales, conceptos como «herir», «desjarretar», «arrancar», «esterilidad», «descendencia»... en una madeja de significados difícil de desenredar y racionalizar.

El término para «descendencia» procedente de esta raíz es en hebreo bíblico עִקִ literalmente 'raíz', que aparece en el corpus como hápax legómenon (Lev 25:47, siendo en 1Cro 2:27 un nombre propio). Hartley ${ }^{36}$

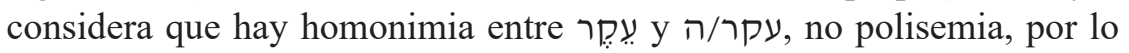
que la racionalización de deriva semántica es impertinente. Mientras tanto, eligiendo una etimología determinada, Barcuh A. Levine ha postulado que:

Interchanging with the image of seed ${ }^{37}$ is that of "root". A barren woman is known as 'aqqārāh (sic) "one deprived of a root," Hebrew 'ēqer (Lev 25:47). The form 'aqqāanh expresses the privative function of the Pi'el (Gen 11:30). It describes a woman whose womb was closed so that the male seed/root could not enter! ${ }^{38}$

36 HaRtLey, רקָำ, pág. 2.

37 Para una discusión del significado que tradicionalmente se ha dado a זרע como 'semen', véase el exhaustivo estudio de Harry M. ORLINSKY, «The Hebrew Root ŠKB», Journal of Biblical Literature 63 (1944) págs. 19-44, especialmente las págs. 36-39.

38 Baruch A. Levine, «'Seed' versus 'Womb': Expressions of Male Dominance in Biblical Israel», en Sex and Gender in the Ancient Middle East: Proceedings of the 47th 
Pace Levine, el adjetivo, tal y como lo ha legado la tradición masorética, carece de reduplicación en la segunda radical. En base a la estrecha correlación semántica, no obstante, considero que no hay que descartar la posibilidad de que se trate de un 'aḍdad, es decir, un fenómeno semántico por el cual una palabra, o en este caso, dos de la misma raíz, signifique simultáneamente $\mathrm{X}$ e $\mathrm{Y}$, siendo $\mathrm{Y}$ una idea opuesta a $\mathrm{X}$.

La raíz עק está ausente en lenguas con una antigüedad mayor que el hebreo bíblico, como el ugarítico y el acadio. Se tiene constancia de ella en material epigráfico de lenguas semíticas noroccidentales, pero en forma verbal ('arrancar') y nominal ('raíz', 'descendencia') ${ }^{39}$. Las formas cognadas que aparecen en lenguas posteriores al hebreo bíblico (arameo targúmico, siríaco, mandeo y árabe) han sido tradicionalmente entendidas con un valor dual: 'estéril' para la mujer e 'impotente' para el hombre. Conviene destacar que, por ende, el uso más antiguo atestiguado de la palabra corresponde a la Biblia Hebrea.

En el escenario que plantea el presente artículo, se habría producido una deriva semántica trasversal en las lenguas semíticas que cuentan con esta raíz. El proceso habría implicado que el resultado (persona $\sin (ע)_{1}$ ), significado original, se confundiera con la causa

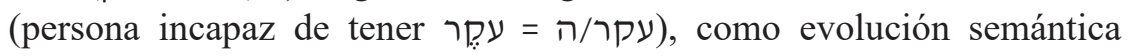
paralela a una mejor comprensión de la esterilidad humana, ya patente en la Mishná (Bekhorot 44b). El valor de 'estéril' para este adjetivo, ya sea masculino o femenino, se mantiene en hebreo moderno ${ }^{40}$.

La traducción de la Septuaginta podría reflejar un momento de la evolución del término en el que al menos el femenino עקרה ya se en-

Rencontre Assyriologique Internationale, eds. Simo Parpola y Robert M. Whiting (Helsinki: Neo-Assyrian Text Corpus Project, 2001) págs. 337-343: 342.

39 Jacob HoftiJzer y Karel Jongeling, Dictionary of the North-West Semitic Inscriptions vol. 2 (Leiden-New York-Köln: Brill, 1995) págs. 882-883.

${ }^{40}$ La expresión חשוך ילדים ha venido a ocupar el lugar posiblemente original de עקר para indicar ausencia de prole. En el año 2010, en el foro <www.tapuz.co.il>, se acuñaba en hebreo moderno un nuevo término para diferenciar entre aquella persona que no tiene descendencia por circunstancias vitales o biológicas (חשוך ילדים resignificado) y aquella que ha decidido no tenerla por razones personales: אלהורות (morfológicamente 'amaternidad / aparternidad'), que se declina como adjetivo אלהורי ('apadre') y אלהורית ('amadre'). Aún no se encuentra admitido por la Academia de la Lengua Hebrea, a pesar de su extendido uso en ciertos sectores de la sociedad israelí. 
tendía como 'estéril', a pesar de los indicios paralelísticos y sintácti$\cos ^{41}$. El griego de Deut 7:14, por su parte, es prueba complementaria de que la comunidad judía ya entendía el adjetivo con ese carácter dual, en función del sexo al que calificara. No debe descartarse, sin embargo, que la traducción de la Septuaginta obedezca aquí a cuestiones ideológicas, quizá influidas por el propio griego, que posteriormente se convirtieran en un lugar común en la traducción bíblica.

La necesidad de cuestionar si se concebía la esterilidad, ya sea masculina o femenina, en el Antiguo Israel que nos lega el testimonio bíblico viene reforzada por dos expresiones idiomáticas hebreas: «abrir y cerrar el vientre», que tienen por sujeto a la deidad:

t) Gen $30: 22$

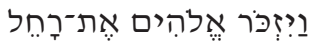

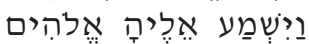

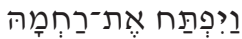

u) $1 \mathrm{Sa} 1: 5$

v) Gen $20: 18$

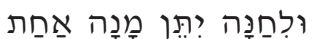

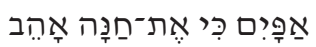

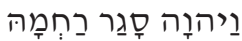

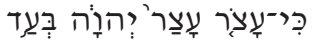

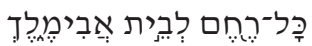

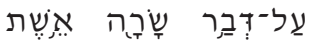
אַבְרָהָם
Dios recordó a Raquel. La escuchó 'Elohīm y abrió su vientre.

Pero a Ana le dio una porción doble [de comida], porque Ana era [la] amada, pero YHWH había cerrado su vientre.

Puesto que ciertamente había bloqueado YHWH todo vientre perteneciente a la casa de Abimélej por el asunto de Sara, mujer de Abraham.

La anatomía sexual femenina, en lo concierne al vientre, es conceptualizada en la Biblia como un receptáculo con puertas (Job 3:9) ${ }^{42}$, quizá no tan figurativamente como se podría pensar hoy. Es la divinidad quien tiene la potestad de cambiar el estado uterino: no solo abre el vientre de

41 Para Gen 30:3, asistimos a un intento de armonización en el griego de la LXX,

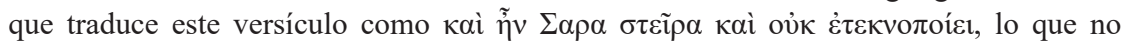
corresponde עקרה אין לה ילד, sino a עקרה לא ילדה עa ש,", expresión esta última más habitual en el corpus bíblico.

42 Las referencias a la puertas de los órganos sexuales femeninos son también comunes en la poesía erótica acadia, aunque en esta el referente es la vulva; $c f$. Nathan Wasserman, Akkadian Love Literature of the Third and Second Millennium BCE (Wiesbaden: Otto Harrassowitz, 2016) págs. 39-40. 
una mujer $(\mathrm{t})$, sino que también puede cerrarlo $(\mathrm{u}, \mathrm{v})^{43}$. Si se creyera que la fertilidad es el estado natural y predeterminado del útero, se hablaría de cerrarlo, pero no de abrirlo. En caso de que pensara que lo es la infertilidad, se hablaría contrariamente de abrirlo, no de cerrarlo. El hecho de que se empleen ambas expresiones se traduce en que es la divinidad quien confiere el don de la concepción (Rut 4:13). En palabras de David Mace:

The Bible does not contest the fact that there is a casual connexion between sex intercourse and conception, but it denies that the effect is inevitable or that parents possess the power to ensure issue ${ }^{44}$.

Mientras que el mundo israelita sí habría sido consciente de que la vejez representaba el fin del ciclo reproductivo ${ }^{45}$ (que sin embargo el favor divino podía deshacer, como se demostraba a Sara), la teología yahvista ${ }^{46}$ no habría conceptualizado una esterilidad como incapacidad biológica per se. Más bien, habría creído en una situación desfavorable pero remediable directamente relacionada con el designio divino. No se trata de negar o subestimar los conocimientos médicos en el Próximo Oriente Antiguo: estos están bien atestiguados en los tratados médicos mesopotámicos, y la infertilidad femenina no era una condición desconocida en el mundo acadio, donde la expresión eqel idrānim ('campo de sal') aludía en ocasiones a mujeres estériles ${ }^{47}$. Más bien, se apunta aquí

${ }^{43}$ La terminología ritual acadia es, de nuevo, semejante al hebreo: se habla de abrir los vientres (patahum), atarlos (kașarum) o soltar el nudo que tienen (kișram pațarum); vid. Stol y Wiggermann, Birth in Babylonia, pág. 35.

44 David R. Mace, Hebrew marriage. A sociological study (London 1953) pág. 202.

45 Para un estudio de la creencia en emisiones seminales femeninas en la Antigüedad, en contraposición con la teoría de la semilla única (masculina), véase Pieter W. vaN DER HORST, «Sarah's Seminal Emission: Hebrews 11.11 in the Light of Ancient Embryology», en A Feminist Companion to the Hebrew Bible in the New Testament (Sheffield: Sheffield Academic Press, 1996) págs. 112-135. Sobre el desarrollo judío del principio de epikrateia o predominancia seminal, ya reflejado en Niddah 31a, véase SToL y WIGGERMANN, Birth in Babylonia and the Bible.

46 Una introducción a la teología del Antiguo Testamento continúa siendo la de Gerhard von RAD, Old Testament Theology (London: SCM Press LTD, 1975. 2 vols.).

${ }^{47}$ La interpretación de Nathan Wasserman (Akkadian Love Literature, pág. 99) es que esta expresión comporta una doble denigración: la salinización como consecuencia de la irrigación excesiva implica, en términos metafóricos, una mujer estéril que man- 
a un condicionamiento teológico: la divinidad dispone de la vida y de la muerte, y la concepción depende de su favor, que da y quita a voluntad. Una traducción de עקרה por 'estéril' corre, por lo tanto, el riesgo de injertar un juicio médico incompatible con la omnipotencia divina. Este análisis filológico del discurso revelaría que mujeres bíblicas «estériles» como Sara, Rebeca y Raquel solo son estériles en la traducción. En el original, son solo 'mujeres sin descendencia, que nunca han parido', cuya condición puede cambiar en cualquier momento.

Según un modelo de semántica componencial que sustituya a la traducción y las trampas que esta puede conllevar, los términos barajados hasta ahora se relacionarían entre sí de la siguiente manera ${ }^{48}$ :

- עקרה: adjetivo (animal) (hembra) (sexualmente madura) (no ha parido descendencia) [la descendencia no ha sido concebida]

- משכלה: adjetivo-sustantivo (animal) (hembra) (sexualmente madura) (no ha parido descendencia) [la descendencia sí ha sido concebida]

- אם: sustantivo (animal) (hembra) (sexualmente madura) (ha parido descendencia) [la descendencia sigue viva]

- שכולה: adjetivo (animal) (hembra) (sexualemente madura) (ha parido descendencia) [la descendencia ha fallecido]

\section{USO REPRODUCTIVO DE ESCLAVAS-ESPOSAS}

En el mundo antiguo, la ausencia de prole (especialmente de varones) entrañaba un problema socioeconómico: ¿quién heredaría el patrimonio familiar? La Biblia Hebrea ha dejado testimonio de varias vías con las que se buscaba «abrir el vientre». De peor a mejor reflejada en el corpus, se encuentra primero la práctica del consumo de hierbas a las que se atribuían propiedades curativas. La planta (דודאים, presumiblemente Mandragora atutumnalis) por la que Raquel cede una noche con Jacob

tiene relaciones con múltiples hombres. Las imágenes que equiparan a las mujeres con campos de arado y a los hombres con agricultores que siembran la semilla es universal en literaturas de civilizaciones agrícolas. Otras metáforas agrícolas sexuales se han mencionado en profundidad en la nota 12 .

48 Los signos significan: categoría de la palabra (marcadores semánticos) [diferenciadores]. 
remite a ritos médico-mágicos que debieron haber disfrutado de gran credibilidad en el Antiguo Israel (Gen 30:14-16), así como en el resto del Próximo Oriente Antiguo ${ }^{49}$. El segundo resorte es la plegaria: Rebeca deja de ser 'aqarâ cuando Isaac reza al dios de su padre (Gen 25:21), y lo mismo ocurre tras la intermediación de Abraham con las mujeres de Guerar (Gen 22:17-18). En tercer y último, lugar se encuentra la práctica de adopción o legitimación ${ }^{50}$, que puede adquirir tres formas distintas.

La primera de ellas es de tipo intrafamiliar, por la cual un pariente adopta a otro. A mediados del siglo pasado, se demostró que Gen 48:5 pertenecía al lenguaje formular adoptivo ya reflejado en el párrafo 170 del Código de Hammurabi y en testimonios ugaríticos ${ }^{51}$. Así, este versículo se desempolvaba como la prueba más fidedigna del protocolo de los ritos de adopción en el Antiguo Israel: eran efectuados por la mera proclamación.

El segundo tipo concierne a los esclavos. Es la historia de Damasco Eliezer, siervo de Abraham, que si bien nunca fue acogido como hijo, el relato hace llegar la angustia que genera al patriarca la posibilidad de que este herederara (Gen 15:2-3), lo cual da fe de la existencia de este tipo de contratos en el Antiguo Israel.

El tercer formato de adopción, y el que más aparece en la narrativa bíblica, es el de la descendencia parida por la esclava de la esposa. Las narraciones bíblicas de las tres matriarcas de Israel aparecen hiladas con

49 La epopeya de Etana, rey mitológico de la ciudad sumeria de Kish, narra la búsqueda de la "planta de la concepción" (šamma ̌̌a alādi), que se encuentra en posesión de los dioses. El paralelo con la mandrágora de Raquel no ha pasado desapercibido en los estudios bíblicos. Para una traducción del relato babilónico al inglés, véase Stephanie DAlley, Myths from Mesopotamia: Creation, the Flood, Gilgamesh, and Others (Oxford: W. Ross MacDonald School Resource Services Library, 2009) págs. 189-202.

50 La apelación al concepto de adopción en un contexto bíblico cuenta con una larga tradición académica, especialmente en lo que se refiere a la discusión de Gen 30:3. El término de «legitimación» ha sido preferido por Thomas L. THOMPSON (The Historicity of the Patriarchal Narratives: the Quest for the History of Abraham [Berlin: Walter de Gruyter, 1974]). Para un estado de la cuestión, véase Herbert DoNNER, «Adoption oder Legitimation? Erwagungen zur Adoption im Alten Testament auf dem Hintergrund der altorientalischen Rechte», Oriens Antiquus 8 (1969) págs. 87-119.

51 Isaac Mendelsohn, «A Ugaritic Parallel to the Adoption of Ephraim and Manasseh», Israel Exploration Journal 9:3 (1959) págs. 180-183. 
la condición de 'aqarâ como leitmotiv teológico. Para revertir la situación, Sara entrega a Hagar a su marido, con el deseo de «construirse a partir de ella» (Gen 16:2). Rebeca también es descrita como 'aqarâ, aunque sus circunstancias y desenlace se resumen en un simple versículo (Gen 25:21). Raquel y Lea, hermanas de sangre y primas de Jacob, mantienen una relación de absoluta enemistad a lo largo de la narración de su historia compartida. Una es descrita en contraposición con la otra de forma sistemática: Lea es la hermana fea y Raquel, la hermosa (Gen 29:17); Lea es la esposa odiada y Raquel, la amada (Gen 29:30-31); Lea es quien pare y Raquel, la que no (Gen 29:31); Lea compite contra su hermana y Raquel la envidia. Pronto se desarrolla una verdadera carrera reproductiva entre hermanas. Desesperada, Raquel increpa a su marido:

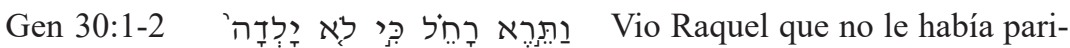

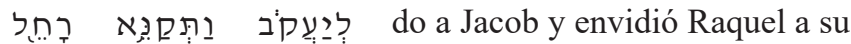
hermana. Le dijo a Jacob: «Dame

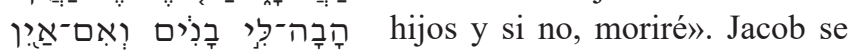

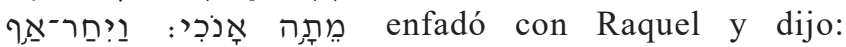

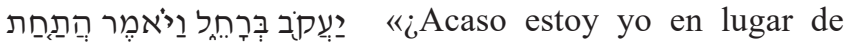

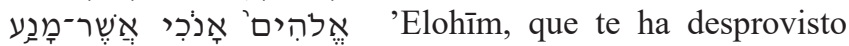

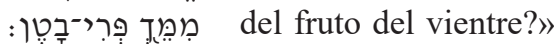

Este fragmento ilustra cómo la maternidad constituye el objetivo vital de la mujer israelita, que prefiere la muerte a una vida sin descendencia, y refuerza la teoría de la inexistencia del concepto de esterilidad, tanto femenina (la divinidad quita y da) como especialmente masculina (el hombre no tiene parte en la decisión divina). Sugerir lo contrario hiere el ego masculino: si Jacob no había mostrado hostilidad alguna ante la condición de 'aqarâ de Raquel y no había menguado su amor por ella, sí se despliega su ira al sentir la responsabilidad vertida sobre sí mismo.

En el versículo siguiente (Gen 30:3), Raquel, siguiendo los pasos y palabras de Sara, entrega su esclava Bilha a Jacob, deseando «construirse a partir de ella». A esta fórmula le había antecedido otra: «ella [Bilha]

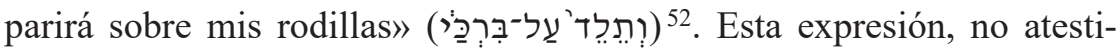

52 El eco de las palabras de Raquel a Jacob sobre su esclava Bilha acabó resonando en el mundo literario. En la década de los ochenta, Margaret ATwood convertía esta 
guada en otras lenguas semíticas y solo una segunda vez en el corpus hebreo bíblico (Gen 50:23), ha generado gran debate y dividido la opinión académica en dos sectores. Mayoritariamente, se ha optado por entender la expresión como literal, donde la forma de parto es descrita conforme a un ritual de adopción/legitimación ${ }^{53}$.

Una faceta menos explorada de esta expresión es la práctica obstétrica descrita, por la cual la esposa legítima actúa de facto como soporte humano de la parturienta. Soranus, médico griego del siglo I/II e.c., ofrece un testimonio sobre un tipo de asiento con forma de taburete y señala cómo actuar en su ausencia:

[...] one must make [the gravida] get up and place her on the socalled midwife's stool [...]. But if the midwife's stool is not at hand, the same arrangement can also be made if she sits on a woman's lap ${ }^{54}$.

interpretación literal del versículo en el cimiento argumental de su distopía misógina The Handmaid's Tale (Toronto: McClelland and Stewart, 1985), recientemente retomada en The Testaments (Toronto: Nan A. Talese-Doubleday, 2019). Durante la Tercera Ola, no será sorprendente encontrar obras de inspiración bíblica y corte feminista, como la reelaboración de la violación de Dina en Gen 34 por Anita Diamant en The Red Tent (New York: Picador, 1997) o la narración de Athalya BRENNER en primera persona de las historias de algunos personajes bíblicos femeninos en I am: Biblical Women Tell Their Own Stories (Minneapolis: Fortress Press, 2004). Para una reescritura en clave lésbica de la historia de Ruth y Noemí, véase Clara CARBonell OrTIZ, «El libro de la moabita», en Herstoria I. Relatos de ficción historia protagonizados por mujeres LBT+ (Murcia: LES Editorial, en prensa).

53 Véase StADE, «Miscellen: 12. Mich. 2, 4. 13. Die vermeintliche Königin des Himmels. 14. Der Hügel der Vorhäute Jos. 5. 15. Auf Jemandes Knieen gebären. Gen. 30, 3. 50, 23. Hiob 3, 12 und Exod. 1, 16. 16. Anmerkungen zu 2 Kö. 15-21», Zeitschrift für die Alttestamentliche Wissenschaft 6 (1886) págs. 122-189; Ephraim A. SPEISER, Genesis (New York: Doubleday, 1964); VAn SeTERS, «The Problem of Childlessness»; Sarna, Genesis; Hillel Vered, "Why Not Naphtali?" en Things Revealed: Studies in Early Jewish and Christian Literature in Honor of Michael E. Stone, eds. Esther G. Chazon, David Satran y Ruth A. Clements (Leiden-Boston: Brill, 2004) págs. 279288, y Jeffrey H. Tigay, «Adoption», en Encylopaedia Judaica vol 1, eds. Fred Skolnik y Michael Berenbaum (Detroit: Thomson Gale, 2007) págs. 415-417.

54 Owsei Temkin, (trad.), Soranus' Gynecology (Baltimore: Johns Hopkins Press, 1991) pág. 73. La obra de Soranus sería traducida en la Edad Media al hebreo con el título de ספר תולדת, a partir de la versión latina de Muscio. Véase la edición de Ron BARKAI, Les infortunes de Dinah: le Livre de la generation (Paris: Editions du Cerf, 1991), así como su A History of Jewish Gynaecological Texts in the Middle Ages (Leiden-Boston-Köln: Brill, 1998). 
En el Próximo Oriente Antiguo, se han encontrado varios testimonios arqueológicos de sillas de parto ${ }^{55}$. En el corpus bíblico, hay un único registro de un utensilio similar:

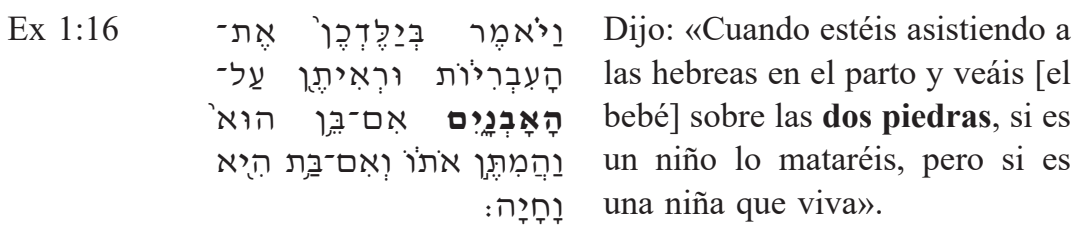

La tradición académica ha interpretado este dual, casi unánimemente, como prueba lingüística de que el instrumento consistía en dos piedras, situándose la parturienta con una rodilla encima de cada cual. No obstante, de las versiones antiguas, solo el Targum de Onkelos lo entendía como un tecnicismo para un instrumento obstétrico (על מתברא); tanto la Septuaginta ( $\pi \rho o ̀ \varsigma \tau \tilde{~} \tau i ́ \kappa \tau \varepsilon v)$ ), como la Vulgata (partus tempus advenerit) y la Peshitta (הכזم) leen un lenguaje figurado que alude a la parturienta. Schökel se opone a 'silla de parto' para entenderlo como un complemento directo sui géneris: «Es posible y probable que אבן represente a veces un alomorfo de Pace Schökel, este tipo de próstatis es un mecanismo propio del singular de sustantivos monosílabicos, no siendo operativo en plural.

55 Utilizo la expresión «silla de parto» como término genérico para aquel utensilio sobre el que se apoya la parturienta y que es usado con el fin de facilitar la apertura del canal del parto, aunque su morfología en la Antigüedad sea muy diferente a la de sillas de parto modernas. Para el taburete egipcio (mshnt) y su múltiple funcionalidad (obstétrica, simbólica y apotropaica), véase el minuicioso studio de Josef WeGNER, «A Decorated Birth Brick from South Abydos: New Evidence on Childbirth and Birth Magic in the Middle Kingdom», en Archaism and Innovation. Studies in the Culture of Middle Kingdom Egypt, eds. David P. Silverman, William K. Simpson y Josef Wegner (New Haven-Philadelphia: Department of Near Eastern Languages and Civilizations [Yale University]-University of Pennsylvania Museum of Archaeology and Anthropology, 2009) págs. 447-496. Para los taburetes acadio (libittu) y sumerio $\left(\operatorname{sig}_{4}\right)$, véase Anne DrafFKORN KILMER, «The Brick of Birth», Journal of Near Eastern Studies 46:3 (1987) págs. 211-213. Para el taburete hitita (harnau), véase Mary Bachvarova, «Hurro-Hittite Stories and Hittite Pregnancy and Birth Rituals», en Women in the Ancient Near East, ed. Mark W. Chavalas (London: Routledge, 2014) págs. 246-271.

56 SCHÖKEL, Diccionario, pág. 30. 
La sustitución de este instrumento por las piernas de otra mujer puede resultar verosímil, pero, en caso de optar por una lectura literal de la expresión, se desplaza el problema a otro versículo: en Gen 50:23, donde también aparece la expresión -לי'יד על ברכ, el sujeto es masculino (José). La presencia de varones durante el parto, acontecimiento perteneciente por excelencia al ámbito de lo femenino, es discutible. La reticencia a que un hombre acompañara a la parturienta aparece quizá reflejada en Os 13:13.

Contrario a esta interpretación literal, Hayim ben Yosef Tawil ha presentado recientemente una propuesta que bebe parcialmente del acadio ${ }^{57}$. El autor analiza la expresión de Raquel como un giro idiomático hebreo donde se emplea un eufemismo genital corriente en lenguas semíticas («rodillas» por «genitales»). La lectura debe ser figurada: 'parirá en lugar de [que lo hagan] mis genitales'. No obstante, el tratamiento lexicográfico de esta expresión es anómalo por parte del autor, puesto que, mientras da a la preposición על un valor de 'en lugar de' para Gen 30:3, lo entiende como 'de' (origen) para Gen 50:23. Hay doble inconsistencia en su tratamiento porque, además, no da acepciones semejantes para la preposición en su correspondiente entrada ${ }^{58}$. Este tipo de tratamiento dual, siendo otro el ya analizado arriba para la pareja de עקר / עקרה aparece reflejado igualmente en las versiones antiguas. Para la expresión de Gen 30:3 y 50:23, respectivamente, la LXX cambiaba

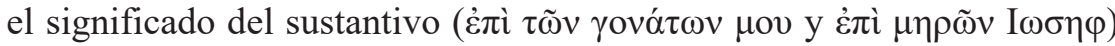
y la Vulgata lo hacía de la preposición (super genua mea e in genibus Ioseph). Estas traducciones antiguas, sumadas al debate académico actual, muestran una vez más cómo el problema interpretativo que se remonta siglos atrás perdura hoy en día, a la espera del descubrimiento de nuevo material lingüístico que sirva de guía y soporte para futuras propuestas.

57 Hayim ben Yosef Tawil, An Akkadian Lexical Companion for Biblical Hebrew. Etymological-Semantic and Idiomatic Equivalents with Supplement on Biblical Aramaic (Jersey City: KTAV Publishing House, 2009) pág. 58.

58 Tawil, An Akkadian Lexical Companion, pág. 277. 


\section{Conclusiones}

El presente artículo ha analizado y dialogado con los discursos de la maternidad, la falta de descendencia y el uso reproductivo de esclavas en el Antiguo Israel desde una perspectiva de género. Con respecto a la maternidad, se ha empleado la etiqueta «expresiones de natividad» para denominar aquellas estructuras morfosintácticas que retratan la llegada de un bebé, y han sido catalogadas y analizadas pormenorizadamente para evaluar cómo se dispone o prescinde de la agencialidad femenina a nivel oracional. En lo que concierne a la ausencia de maternidad, se ha repasado la envergadura semántica y funcionalidad morfológica de las raíces יעק"יר y עי"ד, שכ"ל, haciendo hincapié en la propuesta de un significado de 'sin prole', y no 'estéril', para el lexema עקרה Se postula que el término fue empleado, originalmente, como antónimo de «madre» y que su semántica evolucionó posteriormente para designar la causa (esterilidad) en lugar del mero resultado (ausencia de prole), remediable por actuación divina. En último lugar, se ha discutido la expresión en el contexto de explotación reproductiva de esclavas y repasado el debate académico existente, el cual se antoja irresoluble hasta la fecha por las limitaciones propias del corpus hebreo y por la inexistencia de expresiones cognadas en otras lenguas semíticas.

Recibido: $25 / 03 / 2019$

Aceptado: 07/10/2019 